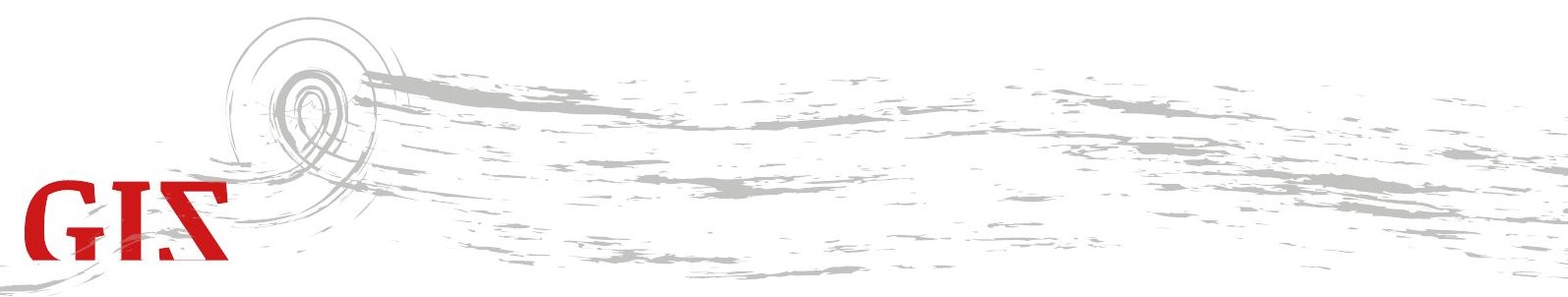

Universidade Nova de RUI MOURÃO Lisboa, Lisboa, Portugal.

\title{
LA MILAGROSA: ENSAIO VISUAL SOBRE RITUAIS E ESTÉTICAS DE SINCRETISMO AFROCUBANO
}

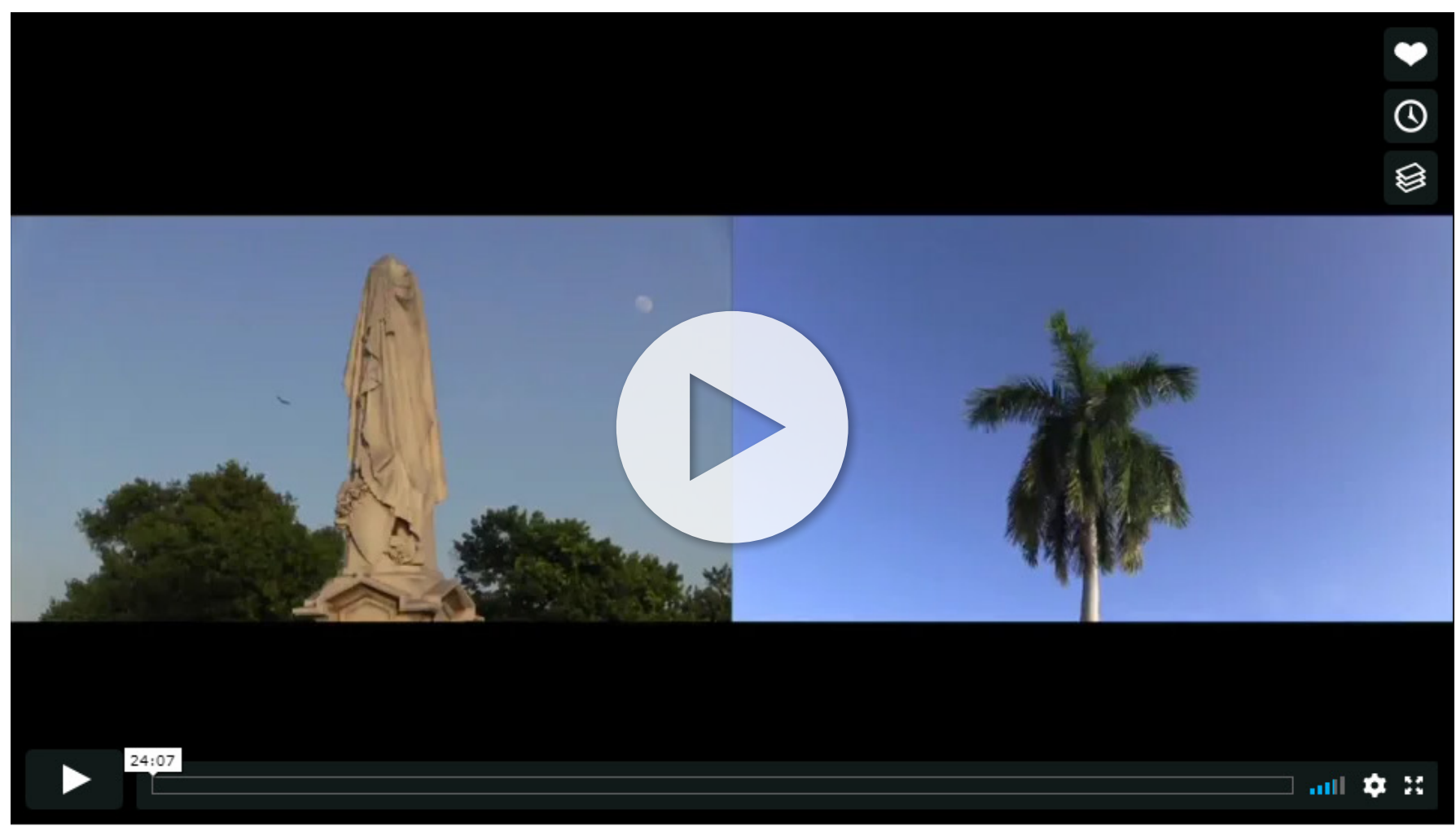

LA MILAGROSA

24'07", 2016

realização, câmera, edição e produção: Rui Mourão entrevistada: Reina "Santera" locações: Casa de Reina "Santera"; (periferia de Havana, Cuba), Cemitério Cristóbal Colón (Havana, Cuba), Santuário Nacional de S. Lázaro (Cuba). trilha sonora: Canto para Chango (música coral e de tambores para rituais de Santeria, interpretada por Abbilona); música coral sagrada gravada em celebração religiosa (no Santuário Nacional de S. Lázaro). características técnicas da imagem: HD vídeo transferido para H.264, formato 16:9, dispositivo de dupla imagem, com cor e som. 
LA MILAGROSA transporta-nos pelo universo visual da Santería, sincretismo religioso entre divindades africanas e religiosidades católicas que se gerou ao longo do processo de colonização espanhola na ilha de Cuba. Os escravos negros, num contexto de opressão, desenvolveram linguagens e processos religioso-culturais próprios que tanto resultaram da sua assimilação como foram expressando uma significativa resistência pela subversão de sentidos iconográficos e performativos.

Sendo os rituais africanos proibidos, os escravos dissimulavam-nos na adoração a santos católicos, em relação aos quais estabeleciam secretas correspondências formais, simbólicas e místicas relativamente aos seus deuses ancestrais - os orixás (Linares 1993). Tais crenças e práticas religiosas não só se desenvolveram durante o período da escravatura como, historicamente, se perpetuaram para além da sua abolição, da independência do país face ao colonialismo espanhol, do domínio das elites brancas ligadas ao neocolonialismo norte-americano e, inclusive, continuaram a existir num contexto político comunista oficialmente ateu.

Testemunho visual da perpetuação da presença da mitologia Ioruba trazida de África para uma ilha do "Novo Mundo", o vídeo revela um vasto mas subtil panteão de deuses tribais por via de santos, cantos e cores presentes em flores, tecidos, doces, velas, pombas, adornos corporais como boinas às riscas ou colares e pulseiras de contas, entre diversos objetos apropriados para fins místicos (por exemplo: bonecos, conchas, tambores, maracas, plantas vivas, aquários, potes, leques, boomerangs, dinheiro, bolas de bilhar, latas de cerveja, objetos dourados ou acobreados etc.). Nesse aspecto, as práticas religiosas aparecem-nos relacionadas a elementos simbólicos com características estéticas próprias (Casanova 2012; Glean 2011): a água e a cor azul (correspondentes à deusa do mar e da maternidade - Yemaya - sincretizada com a Virgen de Regla, também com manto azul); a variantes cromáticas do amarelo e doces ao paladar (por exemplo: bananas, que correspondem à deusa Oshún, do amor e sensualidade); elementos de madeira, instrumentos de percussão e o vermelho e branco (correspondendo a Changó, o orixá dos tronos, raios, justiça, dança e fogo, evocado por tambores e cânticos, como o "Canto para Changó", que se escuta na banda sonora deste ensaio visual, interpretado por Abbilona, referência histórica na música ritual da Santería; o sincretismo dá-se aqui com São Marcos e Santa Teresa).

LA MILAGROSA conduz o espetador pelos altares domésticos de uma santera (mulher que trabalha com Santería). o percurso inclui tanto o altar santero de maior aparato (dentro da tipologia de colorida encenação geralmente presente nas salas de entrada das casas), como outros mais discretos no quintal, inclusive com elementos mais crus e ligados à natureza (como paus, pedras, búzios e água) resguardados num buraco escuro 
coberto com um tecido (tal como os que existiam escondidos nos fundos das senzalas, onde os escravos praticavam os seus rituais às escondidas).

A narrativa visual sai posteriormente do domínio privado do ritual afrocubano e segue por um espaço público de tipologia católica, mas que se tornou igualmente um lugar icónico da Santería: o Cementerio Cristóbal Colón, em Havana. Durante a época colonial foi assim nomeado em honra do "descobridor" europeu da América. É frequentemente considerado um dos mais belos cemitérios do mundo. No vídeo vê-se uma mulher que caminha em busca de uma campa, entre uma expressiva estatuária fúnebre em mármores de Carrara, do período de grande riqueza das elites brancas coloniais e pós-coloniais. Pelo caminho há um registo etnográfico de quem trabalha, restaura e visita o cemitério (o qual tem vindo a adquirir vocação turística). 0 quotidiano performativo presente no cemitério ganha uma dimensão coreográfica no vídeo por meio da edição.

Após um contínuo traveling seguindo uma longa busca pelo cemitério, heis que a câmera se detém numa campa considerada pela população local como milagrosa. Trata-se da campa de uma mulher chamada Amélia, sepultada em 1903, após dar à luz uma criança que também morreu no parto. Reza a lenda que, quando deveria ser exumada treze anos mais tarde, o corpo da mãe e da criança não só estavam intactos como se haviam movido para se abraçar. A partir dessa história começaram as crenças no poder milagroso da referida campa, sendo atualmente um popular local de peregrinação para pedidos ligados a questões de fertilidade, gravidez e parto.

Por fim, o vídeo apresenta imagens noturnas de uma das maiores procissões de Cuba, com milhares de pessoas, primeiro em direção ao santuário de São Lázaro e, posteriormente, já no seu interior. A importância do santuário deve-se a São Lázaro corresponder ao orixá Babalú-Ayé, curador de enfermidades. 0 vídeo documenta como há nessa procissão uma série de práticas católicas impregnadas da presença cultural negra ligada à performatividade do corpo e a elementos como a água (a água benta da igreja e água em copos para dar aos santos na Santería) ou como o fogo e o fumo (acendendo-se velas roxas e fumando-se charutos no templo). Há quem se vista de serapilheira evocando São Lázaro mendigo. Salienta-se, ainda, que as flores e velas oferecidas têm a cor roxa por ser a cor que corresponde ao orixá Babalú-Ayé.

Em suma, este ensaio visual documenta uma série de ações, experiências e ambientes que sustentam a importância do ritual como sistema cultural de comunicação simbólica com sequências padronizadas, as quais são expressas por meios, performatividades e agentes diversos. Nesse sentido, tal como quaisquer outras sequências rituais, também 
estas "têm conteúdo e arranjos caracterizados por graus variados de formalidade (convencionalidade), estereotipia (rigidez), condensação (fusão) e redundância (repetição)" (Peirano 2003, 11).

Do ponto de vista formal, o vídeo recorre a jogos duplos de imagens lado a lado, visando combinações de sentidos em que não seja apenas: imagem $A$ + imagem $B=$ sentido $A B$; mas sim: imagem $A+$ imagem $B=$ sentido ABC. Ou seja, visa-se que o significado da simultânea combinação das imagens seja não só superior ao mero significado das mesmas imagens individuais apresentadas separadamente, como reverbere novos sentidos gerados por essa combinação.

Dentro da linha de trabalho artístico desenvolvida por Rui Mourão, verifica-se que esta obra adota a vídeoarte como meio, a antropologia visual como processo e a dimensão performativa de práticas culturais como objeto de análise.

\section{REFERÊNCIAS BIBLIOGRÁFICAS}

Casanova, Manuel Martínez. 2012. Las religiones negras de Cuba. La Habana: Política.

Glean, Manuel Rivero. 2011. Deidades cubanas de origen africano. La Habana: Abril.

Linares, Maria Teresa. 1993. La santería en Cuba. Gazeta de Antropología, vol. 10, artigo 9. Disponivel em: <https://goo.gl/r5Q7i7>. Acesso em: 5 dez. 2017.

Mourão, Rui. 2016 (Vídeo HD H.264, 16:9, cor 24'07"), Realização, captação, edição e produção. Entrevistada. Reina "Santera"; localizações: Casa de Reina "Santera" (periferia de Havana, Cuba), Cemitério Cristóbal Colón (Havana, Cuba), Santuário Nacional de S. Lázaro (Cuba); trilha sonora: Canto para Chango (música coral e de tambores para rituais de Santeria, interpretada por Abbilona); música coral gravada em celebração católica (no Santuário Nacional de S. Lázaro); Link https:// goo.gl/7DarRt - senha: moving

Peirano, Mariza. 2003. Rituais ontem e hoje. Rio de Janeiro: Zahar. Disponível em: <https:// goo.gl/QSPJ9y>. Acesso em: 5 dez. 2017. 


\section{RUI MOURÃO}

Rui Mourão (1977, Lisboa) estudou Artes na Universitat Autònoma de Barcelona e no Centre d'Estudis Cinematogràfics de Catalunya, na Associação Maumaus, em Lisboa, e na Malmö Art Academy, e, Malmö. Pós-graduação em Culturas Visuais Digitais e Mestrado em Antropologia pelo Instituto Universitário de Lisboa. Doutorando em Estudos Artísticos pela Universidade Nova de Lisboa). Faz videoarte (foi selecionado para o LOOP - Video Art Festival, em Barcelona; recebeu o Prémio do Público no FUSO - Anual de Videoarte Lisboa; estreou um filme na Cinemateca Portuguesa, nomeado para melhor documentário no Festival Queer Lisboa). Fez residências

recebido 13.03.2017 aprovado 01.05.2017 artísticas, performances, palestras, artigos, dois livros (um individual, outro coletivo) e mais de 50 exposições em 16 países (Spaces, Cleveland; Iklectik Art-Lab, Londres; MNAC, Lisboa; Palazzo Albrizzi, Veneza; Museu Nacional de Etnologia, Lisboa; Künstlerhaus Bethanien, Berlim). 